\title{
Farinha de sementes germinadas de abóbora: Aspectos físicos, físico-químicos e colorimétricos
}

Sprouted pumpkin seed flour: Physical, physical-chemical and colorimetric aspects

Harina de pepitas de calabaza germinadas: Aspectos físicos, físico-químicos y colorimétricos

Recebido: 15/02/2021 | Revisado: 17/02/2021 | Aceito: 04/03/2021 | Publicado: 11/03/2021

Lumara Tatiely Santos Amadeu

ORCID: https://orcid.org/0000-0001-7969-2959

Universidade Federal de Campina Grande, Brasil

E-mail: lumaratatielyea@gmail.com

Alexandre José de Melo Queiroz

ORCID: https://orcid.org/0000-0002-6880-5951

Universidade Federal de Campina Grande, Brasil

E-mail: alexandrejmq@gmail.com

Rossana Maria Feitosa de Figueirêdo

ORCID: https://orcid.org/0000-0002-6187-5826

Universidade Federal de Campina Grande, Brasil

E-mail: rossanamff@gmail.com

Yaroslávia Ferreira Paiva

ORCID: https://orcid.org/0000-0002-2096-2122

Universidade Federal de Campina Grande, Brasil

E-mail: yaroslaviapaiva@gmail.com

João Paulo de Lima Ferreira

ORCID: https://orcid.org/0000-0003-1172-7259

Universidade Federal de Campina Grande, Brasil

E-mail: joaop_1@hotmail.com

Carolaine Gomes dos Reis

ORCID: https://orcid.org/0000-0003-1895-9116

Universidade Federal de Campina Grande, Brasil

E-mail: carolainetecalimentos@gmail.com

Renato Costa da Silva

ORCID: https://orcid.org/0000-0003-3172-4776

Universidade Federal de Campina Grande, Brasil

E-mail: renatinocosta@gmail.com

Karoline Thays Andrade Araújo

ORCID: https://orcid.org/0000-0002-9356-3288

Universidade Federal de Campina Grande, Brasil

E-mail: karoline_thays@hotmail.com

Nycolle Oliveira Coelho

ORCID: https://orcid.org/0000-0003-4283-7186

Universidade Federal de Campina Grande, Brasil

E-mail: nycolleoliveirac@gmail.com

Ely Félix de Sá Carneiro

ORCID: https://orcid.org/0000-0002-9316-9651

Universidade Federal de Campina Grande, Brasil

E-mail: elyfelixsc@gmail.com

\begin{abstract}
Resumo
A abóbora (Cucurbita moschata) é uma hortaliça apreciada por pessoas de todos os níveis de renda, porém, suas sementes são descartadas, caracterizando um desperdício em virtude da sua rica composição nutricional. Uma das formas de minimizar esse descarte é disponibilizar alternativas de uso da semente, aumentando seu atrativo para industrialização e consequentemente as possibilidades da sua aplicação na elaboração de alimentos para o consumo humano. Desse modo, objetivou-se avaliar as características físicas, fisico-quimicas e colorimétricas das sementes de abóbora in natura, germinadas e da farinha da semente de abóbora germinada. As amostras foram caracterizadas quanto a massa específica unitária, real e aparente, porosidade, cor, volume, comprimento, largura, espessura, circularidade, esfericidade, teor de água, atividade de água, $\mathrm{pH}$, acidez total titulável, cinzas, lipídios, proteínas, açucares totais e redutores, determinou-se ainda as isotermas de adsorção de umidade das farinhas secas em temperaturas de 20,25 e $30^{\circ} \mathrm{C}$. Verificou-se que o modelo de Peleg, seguido do modelo de Oswin, foram os que apresentaram os melhores ajustes aos dados experimentais. A germinação alterou a massa unitária, porosidade, os
\end{abstract}


parâmetros colorimétricos e gerou um aumento considerável no teor de proteínas. A secagem provocou transformações na massa unitária, porosidade, circularidade e esfericidade. Quanto aos parâmetros físico-químicos, houve redução do pH e açucares redutores e aumento dos teores de lipídios e proteínas. Sendo assim, a farinha de semente de abóbora germinada apresentou bons resultados, principalmente em relação ao teor de proteínas, apresentando-se como uma boa alternativa para o desenvolvimento de novos produtos.

Palavras-chave: Cucurbita moschata; Germinação; Secagem; Isotermas; Caracterização.

\begin{abstract}
The pumpkin (Cucurbita moschata) is a vegetable appreciated by people of all income levels, however, its seeds are discarded, characterizing a waste due to its rich nutritional composition. One of the ways to minimize this disposal is to provide alternatives for using the seed, increasing its attractiveness for industrialization and consequently the possibilities of its application in the preparation of food for human consumption. Thus, the objective was to evaluate the physical, physico-chemical and colorimetric characteristics of fresh, germinated pumpkin seeds and the flour of germinated pumpkin seeds. The samples were characterized in terms of unit specific density, real and apparent, porosity, color, volume, length, width, thickness, circularity, sphericity, water content, water activity, $\mathrm{pH}$, total titratable acidity, ash, lipids, proteins, total and reducing sugars, it was also determined the moisture adsorption isotherms of dry flours at temperatures of 20,25 and $30^{\circ} \mathrm{C}$. It was found that the Peleg model, followed by the Oswin model, were the ones that presented the best adjustments to experimental data Germination changed the unit mass, porosity, colorimetric parameters and generated a considerable increase in protein content. The drying caused transformations in the unit mass, porosity, circularity and sphericity. As for the physical-chemical parameters, there was a reduction in $\mathrm{pH}$ and reducing sugars and an increase in the levels of lipids and proteins. Thus, the germinated pumpkin seed flour showed good results, mainly in relation to the protein content, presenting itself as a good alternative for the development of new products.
\end{abstract}

Keywords: Cucurbita moschata; Germination; Drying; Isotherms; Characterization.

\title{
Resumen
}

La calabaza (Cucurbita moschata) es una hortaliza apreciada por personas de todos los niveles económicos, sin embargo, sus semillas son descartadas, caracterizándose un desperdicio por su rica composición nutricional. Una de las formas de minimizar esta disposición es brindar alternativas de uso de la semilla, aumentando su atractivo para la industrialización y consecuentemente las posibilidades de su aplicación en la preparación de alimentos para consumo humano. Así, el objetivo fue evaluar las características físicas, físico-químicas y colorimétricas de las semillas de calabaza frescas germinadas y la harina de semillas de calabaza germinadas. Las muestras se caracterizaron en términos de masa específica unitaria, real y aparente, porosidad, color, volumen, longitud, ancho, espesor, circularidad, esfericidad, contenido de agua, actividad de agua, pH, acidez total titulable, cenizas, lípidos, proteínas, total y azúcares reductores, también se determinó las isotermas de adsorción de humedad de las harinas secas a temperaturas de 20,25 y $30^{\circ} \mathrm{C}$. Se encontró que el modelo de Peleg, seguido del modelo de Oswin, fueron los que presentaron mejores ajustes a los datos experimentales La germinación cambió la masa unitaria, la porosidad, los parámetros colorimétricos y generó un aumento considerable en el contenido de proteínas. El secado provocó transformaciones en la unidad de masa, porosidad, circularidad y esfericidad. En cuanto a los parámetros físicoquímicos, hubo una reducción del pH y azúcares reductores y un aumento de los niveles de lípidos y proteínas. Así, la harina de pepita de calabaza germinada mostró buenos resultados, principalmente en relación al contenido de proteínas, presentándose como una buena alternativa para el desarrollo de nuevos productos.

Palabras clave: Cucurbita moschata; Germinación; El secado; Isotermas; Calificación.

\section{Introdução}

A abóbora (Cucurbita mochata), conhecida como abóbora de leite ou jerimum de leite, é uma hortaliça pertencente à família Cucurbitaceae, sendo apreciada nos mais diversos preparos, apresentando assim um grande valor econômico e social (Embrapa, 2010; Veronezi \& Jorge, 2011). É uma fonte rica em vitaminas do complexo B, vitamina C, fibra alimentar, minerais (como potássio, fósforo, cálcio, sódio, magnésio, ferro e cloro) e carotenoides, aportando elementos importantes para a saúde humana, inclusive com propriedades antioxidantes, colaborando tanto para a redução do desenvolvimento de doenças do coração, quanto câncer (Anjos et al., 2017).

Segundo o Censo Agropecuário de 2017, foram produzidas no Brasil cerca de 417.839 mil toneladas de abóbora em 78.671 mil hectares, onde o Nordeste contribuiu com 30,3\% da produção nacional, sendo Bahia, Pernambuco e Maranhão os maiores produtores da região (IBGE, 2017). Segundo Del-Vechio (2004), cerca de 3,32\% da massa do fruto correspondem ao 
peso das sementes. Assim tem-se aproximadamente 13.919 toneladas de sementes que não são aproveitadas e normalmente são descartadas. Tratando-se de um desperdício, visto que contém elevados teores de lipídios, proteínas e fibras alimentares (Anjos et al., 2017).

Uma alternativa para minimizar esse descarte seria aprimorar o valor nutricional das sementes, aumentando seu atrativo para industrialização e consequentemente as possibilidades da sua aplicação na elaboração de alimentos para o consumo humano. O processo germinativo apresenta-se como um dos mais antigos, simples e econômicos empregados para essa finalidade (Almeida et al., 2019), pois promove através de transformações bioquímicas, uma potencialização de nutrientes, principalmente em relação ao teor proteico (Amistá \& Tavano, 2013), além de contribuir para a redução de fatores antinutricionais (Aguilera et al., 2013).

Porém, somente a germinação não é totalmente eficaz, pois promove o acréscimo do teor de água da semente (Komatsuzaki et al., 2007), consequentemente diminuindo sua vida útil, o que por sua vez, dificulta a comercialização. Sendo assim, há a necessidade de associação ao método de secagem, pois nesse processo ocorre a diminuição do teor de água das sementes, resultando na redução do metabolismo da mesma, o que colabora com a ampliação do período de armazenamento (Oliveira et al., 2010; Silva et al., 2016), além da concentração dos nutrientes.

Silva e seus colaboradores (2020) afirmam que tanto os grãos germinados, quanto suas respectivas farinhas são adequadas para a preparação de alimentos especiais e geram produtos de valor agregado. Dessa forma, objetivou-se caracterizar as sementes de jaca, tanto in natura, quanto germinada e sua respectiva farinha, através de aspectos físicos, físicoquímicos e colorimétricos.

\section{Metodologia}

O trabalho foi desenvolvido no Laboratório de Armazenamento e Processamento de Produtos Agrícolas (LAPPA) da Unidade Acadêmica de Engenharia Agrícola (UAEA), na Universidade Federal de Campina Grande.

Utilizou-se sementes de abóbora (Cucurbita mochata), extraídas de frutos adquiridos no comércio local. Após a sanitização das aboboras em solução de hipoclorito de sódio $(150 \mathrm{ppm})$ durante 15 min e enxágue em água corrente, as sementes foram extraídas, lavadas em água corrente e colocadas em bandejas para eliminação da umidade superficial.

\section{Germinação e secagem das sementes}

A germinação foi conduzida com três repetições de 56 sementes, mantidas em papel germiteste, umedecido com 2,5 vezes a sua massa com água destilada, sendo posteriormente acondicionadas em câmeras do tipo BOD à $25^{\circ} \mathrm{C}( \pm 1)$, durante 48 horas. As coletas das sementes germinadas foram efetuadas em 48 horas, considerando a protrusão ou tamanho da radícula como indicador da germinação e como forma de padronizar a coleta conforme as Regras para Análise de Sementes (Brasil, 2009).

Em seguida, as sementes de abóbora germinadas foram submetidas a secagem em secador convectivo, à temperatura de $70^{\circ} \mathrm{C}$ e velocidade do ar de 1,3 m/s. Em seguida, foram trituradas em liquidificador para obtenção de farinha.

\section{Caracterização das sementes in natura, germinadas da farinha da semente germinada Propriedades Físicas}

As sementes de abóbora in natura, germinadas e farinha da semente germinada foram caracterizadas quanto às propriedades físicas, utilizando os parâmetros: tamanho, forma, volume, massa unitária, massa específica real e aparente e 
porosidade. O tamanho foi determinado por medição das dimensões nos três eixos mutuamente perpendiculares, realizada em 50 exemplares, com o auxílio de paquímetro digital com precisão de $0,01 \mathrm{~mm}$.

A forma foi determinada com auxílio de um retroprojetor, para projeção da imagem do grão na posição de repouso. Esse parâmetro determina a aproximação da forma do produto ao círculo e à esfera, respectivamente. A circularidade foi determinada conforme a Equação 1 e a esfericidade de acordo com a Equação 2.

$$
C=\frac{A_{p}}{A_{e}} 100
$$

Em que: C - circularidade (\%); $\mathrm{A}_{\mathrm{p}}$ - Área projetada do grão em posição de repouso; $\mathrm{A}_{\mathrm{c}}$ - Área do menor círculo de circunscrição do grão.

$$
\emptyset=\frac{d_{i}}{d_{c}} x 100
$$

Em que: $d_{i}$ - diâmetro do maior círculo inscrito na projeção do grão em repouso; $d_{c}$ - diâmetro do menor círculo circunscrito na projeção do grão em repouso.

$\mathrm{O}$ volume foi determinado por meio do deslocamento de massas por pesagem. A semente foi imersa em béquer contendo água destilada, colocado em balança analítica. A imersão da semente foi realizada com a mesma fixada com alfinete entomológico, preso a um suporte móvel, o suficiente para a imersão completa, o mais próximo possível da superfície. O volume foi dado pela relação entre a massa de água deslocada e a massa específica da água.

A massa específica real foi determinada pela relação entre a massa da semente individual, pesado em balança analítica, e o seu volume, determinado previamente. A massa específica aparente foi determinada em béquer de $2000 \mathrm{ml}$, calculada pela relação entre a massa dos grãos e o volume ocupado.

A porosidade foi determinada conforme a Equação 3.

$$
\varepsilon=\left[1-\left(\frac{\rho_{a}}{\rho_{\mathrm{t}}}\right)\right]
$$

Em que: E - porosidade da massa de grãos (\%); $\mathrm{P}_{\mathrm{a}}$ - massa específica aparente $\left(\mathrm{kg} \cdot \mathrm{m}^{-3}\right) ; \mathrm{P}_{\mathrm{r}}$ - massa específica real $\left(\mathrm{kg} \cdot \mathrm{m}^{-3}\right)$.

\section{Propriedades físico-químicas}

Foram determinadas, em triplicata, conforme os procedimentos analíticos do Instituto Adolfo Lutz (IAL) (2008) os parâmetros: teor de umidade, pelo método gravimétrico em estufa a $105^{\circ} \mathrm{C}$; acidez total por titulometria com $\mathrm{NaOH} 0,1 \mathrm{M}$; $\mathrm{pH}$, determinado na semente triturada e dispersa em água destilada, com auxílio de potenciômetro digital; teor de cinzas, por incineração em mufla a $550{ }^{\circ} \mathrm{C}$, com os resultados expressos em porcentagem (p/p). Os açúcares redutores, foram determinados pelo método do ácido dinitrosalicilico (Miller, 1959); os açúcares totais pelo método da antrona (Yemm \& Willis, 1954); o teor de lipídios, pelo método de Folch (1957) e o teor de proteínas, quantificado segundo o método de Kjeldahl, onde se determina o teor de nitrogênio total, sendo a proteína total determinada multiplicando-se o teor de nitrogênio total pelo fator de 6,25. A atividade de água (Aw) foi determinada por leitura direta em Aqualab, modelo 3TE, da Decagon Devices. 


\section{Propriedades Colorimétricas}

Os parâmetros de cor das amostras foram determinados utilizando dez sementes e cinco leituras de cada, colocadas em posição de repouso. As leituras foram obtidas através do colorímetro digital, no sistema de cor CieLab (L*, a* e b*), em que $\mathrm{L}^{*}$ é a luminosidade, a* é a transição da cor verde $\left(-\mathrm{a}^{*}\right)$ para a cor vermelha $\left(+\mathrm{a}^{*}\right)$ e b* a transição da cor azul (-b*) para a cor amarela $\left(+b^{*}\right)$.

Os dados experimentais foram tratados em delineamento inteiramente casualizado (DIC), aplicando-se o Teste de Tukey a 5\% de probabilidade, com o software ASSISTAT versão 7.7 Beta (Silva \& Azevedo, 2016).

\section{Isotermas de adsorção de umidade}

As isotermas de adsorção de umidade das farinhas das sementes germinadas de abóbora, foram determinadas em higrômetro Aqualab modelo 3TE, da Decagon Devices, nas temperaturas de 20, 30 e $40^{\circ} \mathrm{C}$, de acordo com o método especial indireto estático proposto por Capriste e Rotstein (1982), com ajustes dos dados pelos modelos de Oswin, Peleg e GAB (Tabela 1), utilizando-se regressão não linear no software Statistica 7.0. As qualidades dos ajustes aos dados experimentais foram determinadas pelo coeficiente de determinação $\left(\mathrm{R}^{2}\right)$ e pelo desvio percentual médio $(\mathrm{P})$, calculado conforme a Equação 4.

Tabela 1. Modelos matemáticos a serem utilizados para estimar as isotermas de adsorção de água.

Designação $\quad$ Modelo

GAB

$$
X_{\text {eq }}=\frac{X_{m} \cdot \mathrm{C} \cdot \mathrm{K} \cdot \mathrm{a}_{w}}{\left(1-\mathrm{K} \cdot \mathrm{a}_{w}\right) \cdot\left(1-\mathrm{K} \cdot \mathrm{a}_{w}+\mathrm{C} \cdot \mathrm{K} \cdot \mathrm{a}_{w}\right)}
$$

Peleg

$X_{\mathrm{eq}}=k_{1}, a_{w}^{n_{1}}+k_{2} \cdot a_{w}{ }^{n_{n}}$

Oswin

$$
X_{\text {eq }}=\text { a. }\left(\frac{a_{w}}{1-a_{w}}\right)^{b}
$$

Em que: $\mathrm{a}_{\mathrm{w}}$ - atividade de água, adimensional; $\mathrm{X}_{\mathrm{eq}}$ - Teor de água de equilíbrio (bs); $\mathrm{X}_{\mathrm{m}}$ - teor de água na monocamada molecular (bs); C - constante relacionada com o calor de sorção da camada molecular; $\mathrm{a}, \mathrm{b}, \mathrm{K}, \mathrm{k}_{1}, \mathrm{k}_{2}, \mathrm{n}_{1}$ e $\mathrm{n}_{2}$ - constantes do modelo.

Fonte: Autores.

$$
P=\frac{100}{n} \sum_{i=1}^{n}\left|\frac{\left(x_{E x p}-X_{p r e}\right)}{x_{e x p}}\right|
$$

Em que: $\mathrm{P}$ - desvio percentual médio (\%); $\mathrm{X}_{\exp }$ - valores obtidos experimentalmente;

$\mathrm{X}_{\text {pred }}$ - valores preditos pelo modelo; $\mathrm{n}$ - número de dados experimentais.

\section{Resultados e Discussão}

\section{Propriedades Físicas e Físico-Químicas}

Na Tabela 2 têm-se os valores médios da massa unitária, porosidade, massa específica real e aparente das sementes de abóbora in natura e germinadas (antes e após a secagem), com seus respectivos desvios padrões. 
Tabela 2. Valores médios da caracterização física das sementes de abóbora in natura e germinadas (antes e após a secagem), com respectivos desvios padrões.

\begin{tabular}{|c|c|c|c|}
\hline \multirow{2}{*}{ Parâmetro } & \multicolumn{3}{|c|}{ Semente de abóbora } \\
\hline & In natura & Germinada & Germinada (após secagem) \\
\hline $\begin{array}{c}\text { Massa específica real } \\
\qquad\left(\mathrm{g} / \mathrm{cm}^{3}\right)\end{array}$ & $0,83^{\mathrm{a}} \pm 0,01$ & $0,88^{a} \pm 0,04$ & $0,65^{\mathrm{b}} \pm 0,01$ \\
\hline $\begin{array}{l}\text { Massa específica } \\
\text { aparente }\left(\mathrm{g} / \mathrm{cm}^{3}\right)\end{array}$ & $0,42^{a} \pm 0,00$ & $0,42^{\mathrm{a}} \pm 0,00$ & $0,26^{\mathrm{b}} \pm 0,00$ \\
\hline $\begin{array}{l}\text { Massa específica unitária } \\
\qquad(\mathrm{g})\end{array}$ & $0,16^{\mathrm{b}} \pm 0,01$ & $0,17^{\mathrm{a}} \pm 0,00$ & $0,11^{\mathrm{c}} \pm 0,01$ \\
\hline Porosidade (\%) & $0,48^{c} \pm 0,00$ & $0,52^{\mathrm{b}} \pm 0,02$ & $0,59^{\mathrm{a}} \pm 0,01$ \\
\hline Atividade de água & $0,988^{\mathrm{b}} \pm 0,00$ & $0,996^{\mathrm{a}} \pm 0,00$ & $0,512^{\mathrm{c}} \pm 0,00$ \\
\hline $\mathrm{L}^{*}$ & $59,94^{\mathrm{b}} \pm 0,08$ & $59,06^{\mathrm{c}} \pm 0,08$ & $64,43^{\mathrm{a}} \pm 0,08$ \\
\hline$a^{*}$ & $4,52^{\mathrm{b}} \pm 0,05$ & $4,75^{\mathrm{a}} \pm 0,10$ & $4,30^{\mathrm{c}} \pm 0,08$ \\
\hline$b^{*}$ & $26,26^{\mathrm{b}} \pm 0,20$ & $25,72^{\mathrm{c}} \pm 0,20$ & $27,53^{\mathrm{a}} \pm 0,07$ \\
\hline
\end{tabular}

As médias seguidas da mesma letra minúscula nas linhas não diferem estatisticamente pelo teste de Tukey a 5\% de probabilidade. Fonte: Autores.

Pode-se observar que o processo de germinação não ocasionou diferença significativa $(\mathrm{p}<0,05)$ na massa específica real e aparente, porém houveram reduções significativas ( $\mathrm{p}>0,05$ ) nesses parâmetros quanto ao processo de secagem. Resultados semelhantes foram observados em grãos de amendoim (Araújo et al., 2014) e sementes de abóbora (Paksoy \& Aydin, 2004). Esse comportamento dá-se em função dos espaços vazios no interior do grão e da reduzida contração de suas dimensões durante a secagem, de modo que o volume das sementes permanece praticamente constante, enquanto que a massa sofre redução (Goneli et al., 2008). Após ambos os processos (germinação e secagem), a massa específica real foi superior (p > 0,05) à massa específica aparente, comportamento explicado pelos espaços intergranulares considerados na determinação da massa específica aparente (Firmino et al., 2010).

Em relação a massa unitária, porosidade e atividade de água ( $\mathrm{p}>0,05)$, os dois processos estiveram envolvidos, gerando relações diferentes. Andrade e seus colaboradores (2014) relataram resultado semelhando em sementes de abóbora. O aumento da porosidade em função da secagem, também foi constatado por Araújo et al. (2014) e Bande et al (2012) em grãos de amendoim e sementes de melão, respectivamente. $\mathrm{O}$ aumento da massa específica unitária e atividade de água com a germinação e a redução desses mesmos parâmetros com o processo de secagem, estão diretamente relacionados ao teor de água, uma vez que, no primeiro processo ocorre a absorção de água e no segundo ocorre a perda; logo tem-se consequentemente o aumento e a redução, respectivamente, dos parâmetros mencionados.

A germinação proporcionou o aumento do parâmetro $a^{*}$ e redução dos parâmetros b* e L, ou seja, tornou a semente de abóbora apresentaram intensidade de vermelha e azul e tornaram-se mais escuras. A secagem por sua vez promoveu o 
aumento de $\mathrm{L}^{*}$ e $\mathrm{b}^{*}$ e diminuição de $\mathrm{a}^{*}$, o que significa dizer que as sementes tornaram-se mais claras, e apresentaram intensidade de amarelo e verde.

Na Tabela 3 têm-se os valores médios das dimensões ( $a, b$ e c), volume, circularidade e esfericidade, das sementes de abóbora in natura, germinada e germinada após secagem, com respectivos desvios padrões.

Tabela 3. Valores médios das dimensões ( $\mathrm{a}, \mathrm{b}$ e c), volume, circularidade e esfericidade, das sementes de abóbora in natura e germinadas (antes e após a secagem), com seus respectivos desvios padrões.

\begin{tabular}{|c|c|c|c|}
\hline \multirow{2}{*}{ Parâmetro } & \multicolumn{3}{|c|}{ Semente de abóbora } \\
\hline & In natura & Germinada & $\begin{array}{c}\text { Germinada (após } \\
\text { secagem) }\end{array}$ \\
\hline Volume $\left(\mathrm{cm}^{3}\right)$ & $0,19^{\mathrm{a}} \pm 0,01$ & $0,20^{\mathrm{a}} \pm 0,02$ & $0,17^{\mathrm{a}} \pm 0,01$ \\
\hline Comprimento (mm) & $15,69^{\mathrm{a}} \pm 0,24$ & $15,76^{\mathrm{a}} \pm 0,17$ & $15,34^{\mathrm{a}} \pm 0,14$ \\
\hline Largura (mm) & $9,13^{a} \pm 0,17$ & $9,00^{\mathrm{ab}} \pm 0,07$ & $8,67^{\mathrm{b}} \pm 0,19$ \\
\hline Espessura (mm) & $2,69^{\mathrm{a}} \pm 0,07$ & $2,76^{\mathrm{a}} \pm 0,10$ & $2,75^{\mathrm{a}} \pm 0,05$ \\
\hline Circularidade (\%) & $52,27^{\mathrm{a}} \pm 0,45$ & $51,94^{\mathrm{a}} \pm 0,21$ & $48,35^{\mathrm{b}} \pm 0,83$ \\
\hline Esfericidade (\%) & $58,95^{\mathrm{a}} \pm 0,67$ & $58,93^{\mathrm{a}} \pm 0,59$ & $56,67^{\mathrm{b}} \pm 0,69$ \\
\hline
\end{tabular}

As médias seguidas da mesma letra minúscula nas linhas não diferem estatisticamente pelo teste de Tukey a $5 \%$ de probabilidade. Fonte: Autores.

Verifica-se na Tabela 3 que o processo germinativo não ocasionou diferença estatística $(\mathrm{p}<0,05)$ em nenhum dos parâmetros. Enquanto isso, o processo de secagem não proporcionou diferença estatística (p <0,05) no volume, comprimento e na espessura, no entanto promoveu a redução da largura. Essa desuniformidade é característica de produtos agrícolas, porém segundo Botelho et al. (2016) a existência de parte ou de todo o tegumento enrijecido, pode ocasionar estagnação nas dimensões e evitar variações na forma dos grãos. A redução da largura com o processo de secagem foi identificada por Andrade et al. (2014) e Guedes et al. (2011) ao analisarem grãos de abóbora e de soja, respectivamente. Vidal (2007) ao realizar estudos com algumas variedades de abóboras identificou valores de 15,57, 8,32 e 2,50, (comprimento, largura e espessura, respectivamente), para a variedade Menina Brasileira, tamanho M, sendo próximos aos valores encontrados neste trabalho.

O processo de secagem também promoveu a redução dos parâmetros de circularidade e esfericidade, que apresentaram valores abaixo de $60 \%$ o que, segundo Araújo et al. (2015), classifica uma semente como não circular e não esférica.

Estão apresentados na Tabela 4 os valores médios da caracterização química e físico-química das sementes in natura, germinada e da farinha de semente de abóbora germinada seca, com seus respectivos desvios padrões. 
Tabela 4. Valores médios da caracterização química e físico-química das sementes in natura, germinada e da farinha de semente de abóbora germinada seca, com seus respectivos desvios padrões

\begin{tabular}{|c|c|c|c|}
\hline \multirow{2}{*}{ Parâmetro } & \multicolumn{3}{|c|}{ Semente de abóbora } \\
\hline & In natura & Germinada & $\begin{array}{c}\text { Farinha da Semente } \\
\text { Germinada }\end{array}$ \\
\hline Teor de água (b.u) & $32,66^{\mathrm{b}} \pm 0,56$ & $49,60^{\mathrm{a}} \pm 0,77$ & $4,01^{\mathrm{c}} \pm 0,59$ \\
\hline $\mathrm{pH}$ & $6,71^{\mathrm{a}} \pm 0,03$ & $6,40^{\mathrm{b}} \pm 0,03$ & $6,10^{\mathrm{c}} \pm 0,02$ \\
\hline Acidez & $0,24^{\mathrm{b}} \pm 0,02$ & $0,25^{\mathrm{b}} \pm 0,00$ & $0,97^{\mathrm{a}} \pm 0,04$ \\
\hline Cinzas $(\%)$ & $2,84^{\mathrm{b}} \pm 0,13$ & $2,02^{\mathrm{c}} \pm 0,17$ & $3,92^{\mathrm{a}} \pm 0,30$ \\
\hline Lipídios (\%) & $11,54^{\mathrm{b}} \pm 0,72$ & $8,77^{\mathrm{c}} \pm 0,70$ & $20,31^{\mathrm{a}} \pm 0,50$ \\
\hline Proteínas $(\%)$ & $30,13^{\mathrm{c}} \pm 1,05$ & $34,40^{\mathrm{b}} \pm 0,74$ & $48,35^{\mathrm{a}} \pm 0,30$ \\
\hline Açúcares redutores $(\mathrm{g} / 100 \mathrm{~g})$ & $1,31^{\mathrm{b}} \pm 0,04$ & $3,01^{\mathrm{a}} \pm 0,04$ & $1,53^{\mathrm{b}} \pm 0,04$ \\
\hline Açúcares totais (g/100g) & $2,93^{\mathrm{a}} \pm 0,16$ & $2,86^{\mathrm{a}} \pm 0,22$ & $2,95^{\mathrm{a}} \pm 0,16$ \\
\hline
\end{tabular}

As médias seguidas da mesma letra minúscula nas linhas não diferem estatisticamente pelo teste de Tukey a $5 \%$ de probabilidade. Fonte: Autores.

As sementes in natura apresentaram teor de água médio de 32,66 \% b.u., valor inferior ao encontrado por Naves et al (2010) ao estudar abóboras da espécie Cucurbita maxima autor (56,54\%); e superior ao valor médio encontrado por Sant’Anna et al (2005) estudando abóbora da espécie Cucurbita pepo autor (29,24\%). O processo de germinação ocasionou o aumento do teor de água e de acordo com Villela et al (2007) isso ocorre porque durante esse processo ocorre a hidratação das sementes com a finalidade de promover o desenvolvimento da planta; mesmo comportamento foi verificado por Martinez et al (2011) ao comparar grãos de soja antes e após a germinação. A farinha da semente de abóbora germinada seca apresentou teor de água de 4,01\% (b.u), estando abaixo do valor máximo (15\%) estabelecido pela Agência Nacional de Vigilância Sanitária (ANVISA) (2005) para a conservação de farinhas.

$\mathrm{O}$ valor quantificado para o $\mathrm{pH}$ classifica tanto as sementes in natura e germinada quanto a farinha como produtos ligeiramente ácidos, no limite da neutralidade. Tanto o processo germinativo quanto o processo de secagem ocasionaram a redução do pH. Essa redução no caso da farinha, pode ter ocorrido, segundo Alcântara et al. (2007), devido à concentração de ácidos durante a secagem. Segundo Kadam e Balasubramanian (2011) pH inferiores a 4,5 acarretam um crescimento reduzido de microrganismos, e amostras com pH superiores a 4,5 estão propensos ao desenvolvimento de proliferações microbiológicas com maior facilidade. Quanto a acidez, as sementes in natura não diferiram estatisticamente das sementes germinadas, porém diferiram da farinha, constatando-se um aumento.

A determinação dos valores de $\mathrm{pH}$ e acidez titulável fornecem informações quanto à qualidade das farinhas, pois quanto menor o valor de $\mathrm{pH}$ e maior o valor de acidez, maior é a conversão dos ácidos graxos de cadeia longa em ácidos orgânicos de cadeia curta, os quais conferem sabor e odor desagradáveis aos produtos, sendo assim, com valores de pH e 
acidez de 6,43 e 0,59, a farinha de semente germinada de abóbora apresenta-se como uma boa alternativa para o desenvolvimento de novos produtos, como os elaborados por Silva (2012), Freitas et al. (2018) e Morais (2019), que desenvolveram barra de cereal, biscoito e cookies de farinha de semente de abóbora, respectivamente.

Ao comparar a semente in natura com a germinada nota-se que a germinação promoveu a redução dos lipídios, essa redução pode estar relacionada ao fato de que o processo germinativo demanda energia para formação da plântula, assim enzimas hidrolíticas são ativadas, promovendo a decomposição de substâncias moleculares de grande dimensão, como os lipídios e proteínas, em pequenos compostos moleculares (Kaukovirta-Norja et al., 2004; Moongngarm \& Saetung, 2010). Comparando a semente germinada com a farinha observa-se que o processo de secagem ocasionou o aumento dos constituintes, comportamento que pode ser explicado em virtude da concentração resultante da eliminação de parte da água presente.

De acordo com o Ministério da Saúde (Brasil, 2002) são considerados alimentos sólidos ricos em proteínas quando o teor destas for superior a 5\%, desse modo tanto a semente in natura e germinada quanto a farinha se enquadram nessa categoria. As sementes de abóbora in natura detiveram valor médio de $34,40 \%$ para as proteínas, sendo esse valor superior ao reportado por Pumar et al. (2008) e três vezes maior do que o encontrado por Borges et al. (2006) ambos ao estudarem sementes de abóbora. O valor médio de lipídios encontrado para as sementes de abóbora in natura foi 11,54\%, sendo inferior ao reportado por Naves et al. (2010) para sementes de abóbora Cucurbita maxima.

Os açúcares totais não diferiram estatisticamente entre si, no entanto os açúcares redutores apresentaram um aumento após o processo de germinação, comportamento que é resultante da degradação do amido promovida por amilases (Moongngarm \& Saetung, 2010). Tian et al. (2010) analisando sementes de aveia verificaram o aumento dos açúcares redutores com o processo germinativo; os autores reportaram ainda valores de 1,11 (semente crua) e 1,28 (semente germinada após 24 horas) para os açúcares redutores, sendo esses inferiores aos valores médios encontrados para as sementes de abóbora. Mohan et al. (2010) encontraram valor médio para açúcares totais próximo ao da semente in natura ao estudarem o arroz (variedade, Jaya) (1,3). Moongngarm \& Saetung (2010) reportaram valores para açúcares redutores e totais superiores $(10,9$ e 14,6 respectivamente) ao da farinha de semente de abóbora germinada seca ao analisarem o pó de arroz bruto germinado.

\section{Isotermas de adsorção de umidade}

$\mathrm{Na}$ Tabela 5 têm-se os valores dos parâmetros dos modelos de Oswin, GAB e Peleg, ajustados aos dados experimentais das isotermas de adsorção de umidade da semente de abóbora germinada seca, seguido dos respectivos coeficientes de determinação $\left(\mathrm{R}^{2}\right)$, dos desvios percentuais médios $(\mathrm{P})$, nas temperaturas de $20^{\circ} \mathrm{C}, 30^{\circ} \mathrm{C}$ e $40^{\circ} \mathrm{C}$ e seus respectivos coeficientes de determinação $\left(\mathrm{R}^{2}\right)$, desvios percentuais médios $(\mathrm{P})$, desvios quadráticos médios $(\mathrm{DQM})$ e quiquadrados reduzidos $\left(\mathrm{X}^{2}\right)$. 
Tabela 5. Parâmetros dos modelos ajustados às isotermas de adsorção de umidade da farinha de sementes de abóbora germinadas secas, nas temperaturas de 20,30 e $40{ }^{\circ} \mathrm{C}$ e seus respectivos coeficientes de determinação $\left(\mathrm{R}^{2}\right)$, desvios percentuais médios $(\mathrm{P})$, desvios quadráticos médios (DQM) e qui-quadrados reduzidos $\left(\mathrm{X}^{2}\right)$.

\begin{tabular}{|c|c|c|c|c|c|c|c|c|c|}
\hline \multirow{2}{*}{ Modelos } & \multirow{2}{*}{$\mathrm{T}\left({ }^{\circ} \mathrm{C}\right)$} & \multicolumn{3}{|c|}{ Parâmetros } & & \multirow{2}{*}{$\mathrm{R}^{2}$} & \multirow{2}{*}{$\mathrm{P}(\%)$} & \multirow{2}{*}{ DQM } & \multirow{2}{*}{$x^{2}$} \\
\hline & & $\mathrm{a}$ & & $\mathrm{b}$ & & & & & \\
\hline \multirow{3}{*}{ OSWIN } & 20 & 6,3767 & & 0,4741 & & 0,9253 & 8,1789 & 1,0454 & 1,1923 \\
\hline & 30 & 7,1956 & & 0,3967 & & 0,9934 & 2,3812 & 0,2559 & 0,0702 \\
\hline & 40 & 8,4608 & & 0,3657 & & 0,9954 & 2,5028 & 0,2253 & 0,0548 \\
\hline \multirow{4}{*}{ GAB } & $\mathrm{T}\left({ }^{\circ} \mathrm{C}\right)$ & $\mathrm{Xm}$ & $\mathrm{c}$ & $\mathrm{k}$ & & $\mathrm{R}^{2}$ & $\mathrm{P}(\%)$ & $\overline{D Q M}$ & $x^{2}$ \\
\hline & 20 & 3,3201 & 870449,7 & 0,9154 & & 0,9219 & 8,3031 & 1,0689 & 1,3059 \\
\hline & 30 & 3,7050 & 1534594 & 0,8881 & & 0,9690 & 5,6071 & 0,7384 & 0,6059 \\
\hline & 40 & 4,4938 & 1175052 & 0,8650 & & 0,9867 & 4,6341 & 0,4385 & 0,2163 \\
\hline \multirow{4}{*}{ PELEG } & $\mathrm{T}\left({ }^{\circ} \mathrm{C}\right)$ & $\mathrm{k} 1$ & $\mathrm{n} 1$ & $\mathrm{k} 2$ & $\mathrm{n} 2$ & $\mathrm{R}^{2}$ & $\mathrm{P}(\%)$ & DQM & $x^{2}$ \\
\hline & 20 & 11,9410 & 0,7039 & 57,6504 & 20,297 & 0,9887 & 4,1774 & 0,4075 & 0,1993 \\
\hline & 30 & 24,1182 & 11,5891 & 11,6556 & 0,6056 & 0,9944 & 2,2732 & 0,2954 & 0,1007 \\
\hline & 40 & 22,3805 & 8,7358 & 11,9869 & 0,4992 & 0,9967 & 2,3068 & 0,2209 & 0,0573 \\
\hline
\end{tabular}

Fonte: Autores.

Verifica-se que dentre os modelos testados, todos ajustaram-se de forma adequada, uma vez que os coeficientes de determinação $\left(\mathrm{R}^{2}\right)$ foram superiores a 0,9 e os desvios percentuais médios inferiores a 10\%, que segundo Lomauro et al. (1985) seria o ideal. Além disso, segundo Silva et al. (2019) os desvios quadráticos médios e os qui-quadrados reduzidos devem estar próximos a zero, o que igualmente ocorreu com os resultados apresentados.

Entretanto o modelo de Peleg (seguido do modelo de Oswin) apresentou os melhores ajustes por retratar os menores desvios percentuais médios (inferiores a 5\%), os menores $\mathrm{DQM} \leq 0,4075$ e $\mathrm{X}^{2} \leq 0,1993$ e $\mathrm{R}^{2}>0,98$. Lemos et al. (2016) também constataram que o modelo de Peleg foi mais adequado para predizer os ajustes das isotermas de adsorção da semente de noni nas temperaturas de 20,30 e $40^{\circ} \mathrm{C}$.

Analisando o modelo de Oswin nota-se que com o aumento da temperatura os parâmetros "a" e "b" aumentaram e diminuíram, respectivamente, no entanto se mantiveram em um intervalo $(\mathrm{a}>0$ e $1 \geq \mathrm{b}>0$ ) que, de acordo com Blahovec (2004), indica que na curva não há ponto de inflexão, não havendo, portanto, mudanças na concavidade das funções; assim, esses parâmetros apresentaram consistência matemática e física.

Analisando o modelo de GAB, observa-se que a constante $\mathrm{C}$ apresentou valores maiores que 10 e que os valores de $\mathrm{K}$ estão na faixa entre 0 e 1, o que implica em uma isoterma com forma sigmoidal (tipo II), comum para a maioria dos produtos agrícolas, indicando a existência de umidade adsorvida em camadas multimoleculares (Blahovec, 2004). Observa-se também que quanto menor a temperatura, menor o valor da umidade na monocamada (Xm), e consequentemente maior a estabilidade do produto; esse parâmetro indica o teor de água para um armazenamento seguro, uma vez que abaixo desses valores a deterioração é muito pequena, pois a água está ligada fortemente ao produto, não estando, portanto, envolvida em reação de deterioração, seja como solvente ou como um dos substratos (Costa, 2010).

Na Figura 1 tem-se a representação gráfica das isotermas de adsorção de umidade das sementes de abóbora germinadas secas, nas temperaturas de 20,30 e $40^{\circ} \mathrm{C}$, ajustadas pelo o modelo de Peleg. Constata-se que o aumento da temperatura promove o aumento da umidade de equilíbrio; e o aumento da atividade de água resulta no aumento da umidade 
de equilíbrio, comportamento que segundo Medeiros et al. (2006) ocorre porque a pressão do vapor de água contido no produto segue o aumento da pressão de vapor do meio que o envolve. Esse mesmo comportamento, em que a umidade de equilíbrio aumenta com o aumento temperatura e da atividade de água, foi observado ao estudarem a farinha das sementes de jambu in natura (Costa, 2010); do bagaço de jabuticaba gerado no processo de prensagem durante a produção do suco integral (Luchese et al., 2014) e das fibras residuais secas de manga Haden (Silva et al., 2015).

Figura 1. Isotermas de adsorção de água da farinha de sementes de abóbora germinadas secas com ajustes pelo modelo de Peleg, nas temperaturas de 20,30 e $40^{\circ} \mathrm{C}$.

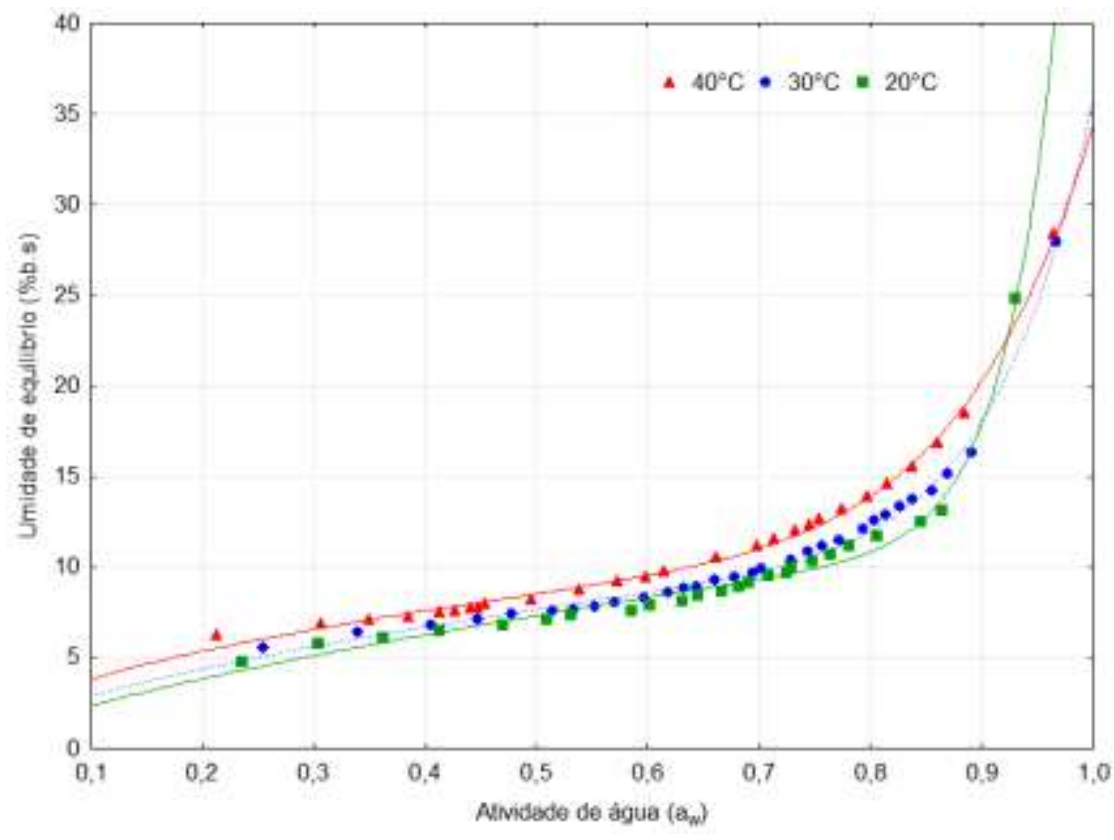

Fonte: Autores.

Percebe-se também que a farinha adsorve pouca quantidade de água quando em baixa atividade de água; adsorve uma maior quantidade de água quando em alta atividade de água e que acima da atividade de água de 0,9 ocorreu uma inversão com a curva a $20{ }^{\circ} \mathrm{C}$. Estas últimas situações ocorrem porque a água exerce forte influência sobre a estabilidade da farinha por estar na forma de moléculas livres, sendo capaz de dissolver componentes, ocasionando acelerações nas reações (Santos et al., 2014). Esse comportamento segundo Telis e Sobral (2001) indica que o produto é rico em açúcares.

Através dessas informações pode-se identificar a embalagem mais apropriada para o armazenamento do produto, o máximo teor de água em que as sementes podem ser armazenadas e determinar o nível de desidratação do mesmo em função das mudanças de temperaturas que podem ocorrer (Venancio, 2015).

\section{Considerações Finais}

As isotermas de adsorção de água das farinhas das sementes de abóbora germinada seca foram classificadas como Tipo II. O modelo de Peleg, seguido do modelo de Oswin, foram os que melhores ajustaram-se aos dados experimentais.

A germinação não ocasionou modificações na maioria das características físicas avaliadas, contudo alterou a massa unitária e a porosidade. Outras alterações foram verificadas nos parâmetros colorimétricos ( $\mathrm{L}^{*}, \mathrm{a}^{*}$ e b*), tornando as sementes mais escuras, resultando em um aumento na intensidade do amarelo e verde. Quanto aos parâmetros físico-químicos, esse processo gerou um aumento considerável no teor de proteínas.

A secagem por sua vez, gerou transformações na massa unitária, porosidade, circularidade e esfericidade. Do mesmo 
modo, propiciou o clareamento das sementes de abobora e gerou tanto a redução do $\mathrm{pH}$ e açucares redutores quanto o intensificou os teores de lipídios e proteínas.

Sendo assim, a farinha de semente de abóbora germinada apresentou bons resultados, principalmente em relação ao teor de proteínas, apresentando-se como uma boa alternativa para o desenvolvimento de novos produtos que visão a suplementação protéica, o que resultaria em uma agregação de valor e consequente redução dos resíduos gerados pelas agroindústrias.

\section{Referências}

Aguilera, Y., Díaz, M. F., Jiménez, T., Benítez, V., Herrera, T., Cuadrado, C., Martín-Cabrejas, M. A. (2013). Changes in nonnutritional factors and antioxidant activity during germination of nonconventional legumes. Journal of Agricultural and Food Chemistry, 61(34), 8120-8125.

Alcântara, S. R., Almeida, F. A. C., \& Silva, F. L. H. (2007). Emprego do bagaço seco do pedúnculo do caju para posterior utilização em um processo de fermentação semi-sólida. Revista Brasileira de Produtos Agroindustriais, 9(2), 137-142. dx.doi.org/10.15871/1517-8595/rbpa.v9n2p137-142.

Almeida, R. L. J., Santos, N. C., dos Santos Pereira, T., de Alcântara Silva, V. M., de Alcântara Ribeiro, V. H., Borges, I. M. S., \& Almeida, R. D. (2019). Effect of germination time on structural properties of azuki bean flour (Vigna agularis) germination Efecto del tiempo de germinación en las propiedades estructurales de la harina de. Research, Society and Development, 9(3), e28932317.

Amistá, M. J. M., \& Tavano, O. L. (2013). Influência da germinação e do processamento térmico na digestibilidade proteica e atividade de inibição de tripsina de grãos de quinoa. Brazilian Journal of Food Technology, 16(1), 52-58. doi.org/10.1590/S1981-67232013005000005.

Andrade, E. T., Teixeira, L. P., Espíndola, J. Z., Figueira, V. G., \& Silva, I. M. (2014). Determinação das propriedades físicas e avaliação da cinética de secagem dos grãos de abóbora. Anais do Congresso Brasileiro de Engenharia Agrícola - CONBEA. Campo Grande, MS, Brasil, 43.

Anjos, C. N., Barros, B. H. S., Silva, E. I. G., Mendes, M. L. M. \& Messias, C. M. B. de O. (2017). Desenvolvimento e aceitação de pães sem glúten com farinhas de resíduos de abóbora (Cucurbita moschata). Arquivos de ciências da saúde (FAMERP), 24(4), 58-62. doi.org/10.17696/2318-3691.24.4.2017.870

ANVISA. Agência Nacional de Vigilância Sanitária. (2005). Resolução RDC n 263, de 22 de setembro de 2005 . Regulamento técnico para produtos de cereais, amidos, farinhas e farelos.

Araújo, W. D., Goneli, A. L. D., Orlando, R. C., Martins, E. A. S., \& Filho, C. P. H. (2015). Propriedades físicas dos frutos de amendoim durante a secagem. Revista Caatinga, 28(4), 170-180. doi.org/10.1590/1983-21252015v28n419rc.

Araújo, W. D., Goneli, A. L. D., Souza, C. M. A., Gonçalves, A. A., \& Vilhasantis, H. C. B. (2014). Propriedades físicas dos grãos de amendoim durante a secagem. Revista Brasileira de Engenharia Agrícola e Ambiental, 18(3), 279-286. doi.org/10.1590/S1415-43662014000300006.

Bande, Y. M., Adam, N. M., Azni, Y., \& Jamarei, O. (2012). Moisture-dependent physical and compression of bitter melon (Citrullus colocynthis lanatus) seeds. International Journal of Agricultural Research, 7(5), 243-254.

Blahovec, J. (2004). Sorption isotherms in materials of biological origin mathematical and physical approach. Journal of Food Engineering, 65(4), 489-495. doi.org/10.1016/j.jfoodeng.2004.02.012.

Borges, S. V., Bonilha, C. M. C., \& Mancini, M. C. (2006). Sementes de jaca (Artocapus integrifólia) e de abóbora (Curcubita moschata) desidratadas em diferentes temperaturas e utilizados como ingredientes em biscoitos tipo cookie. Alimentos e Nutrição, 17(3), 317-321.

Botelho, F. M., Correa, P. C., Botelho, S. de C. C., Vargas-Elias, G. A., Almeida, M. D. S. D., \& Oliveira, G. H. H. de. (2016). Propriedades físicas de frutos de café robusta durante determinação e modelagem. Coffee Science, 11(1), 65-75.

Brasil. Ministério da Saúde. (2002). Alimentos regionais brasileiros. Ministério da Saúde.

Costa, C. M. L. (2004). Caracterização e analise experimental do recobrimento de sementes de jambu (Spilanthes oleracea) em leito fluidizado (Tese de doutorado). Universidade Estadual de Campinas, Campinas, SP, Brasil.

Crapiste, G. H., \& Rotstein, E. (1982). Prediction of sorptional equilibrium data for starch-containing foodstuffs. Journal of Food Science, $47(5), 1501-1507$.

Del-vechio, G. (2004). Efeito do processamento em sementes de abóbora (Cucurbita spp.) sobre os níveis de nutrientes e antinutrientes (Dissertação de mestrado). Universidade Federal de Lavras, Lavras, MG, Brasil.

EMBRAPA. Empresa Brasileira de Pesquisa Agropecuária. (2010). Aspectos técnicos do cultivo da abóbora na região Nordeste do Brasil. Aracajú: Embrapa Tabuleiros Costeiros.

Folch, J., Less, M., \& Stanley, S. (1957). A simple method for the isolation and purification of total lipids from animal tissues. Journal Biological Chemistry, 226(1), 497-509. 10.1016/s0021-9258 (18) 64849-5

Freitas, C., Valente, D. R., \& Cruz, S. P. (2014). Caracterização física, química e sensorial de biscoitos confeccionados com farinha de semente de abóbora (FSA) e farinha de semente de baru (FSB) para celíacos. Demetra: Alimentação, Nutrição \& Saúde, 9(4), 1003-1018.

Goneli, A. L. D., Corrêa, P. C., Botelho, F. M., Oliveira, G. H. H., \& Santos, E. S. (2008). Propriedades físicas dos frutos de mamona durante a secagem. Revista Brasileira de Armazenamento, 33(2), 148-155. 
Guedes, M. A., Mata, M. E. R. M. C., Duarte, M. E. M., \& Farias, P. de A. (2011). Caracterização física de grãos de soja utilizando-se processamento digital de imagens. Revista Brasileira de Produtos Agroindustriais, 13(3), 279-294.

IAL. Instituto Adolfo Lutz. (2008). Normas analíticas do Instituto Adolfo Lutz: métodos químicos e físicos para análises de alimentos. $1^{\circ}$ Ed. Digital. Sao Paulo: Instituto Adolfo Lutz.

IBGE. Instituto Brasileiro de Geografia e Estatística. Sistema IBGE de Recuperação Automática (SIDRA). Censo Agropecuário 2017.

Kadam, D. M., \& Balasubramanian, S. (2011). Foam mat drying of tomato juice. Journal of Food Processing and Preservations, 35(4), 488-495. doi.org/10.1111/j.1745-4549.2010.00492.x.

Kaukovirta-Norja, A., Wihelmson, A., \& Poutanen, K. (2004). Germination: a means to improve the functionality of oat. Agricutural and Food Science, 13, 100-112. 10.2137 / 1239099041838049.

Komatsuzaki, N., Tsukahara, K., Toyoshima, H., Suzuki, T., Shimizu, N., \& Kimura, T. (2007). Effect of soaking and gaseous treatment on GABA content in germinated brown rice. Journal of food engineering, 78(2), 556-560.

Lemos, D. M., Figueiredo, R. M. F., Queiroz, A. J. M., Sousa, E. P., Oliveira, E. N. A. (2016). Obtenção das isotermas de sorção das sementes de noni (Morinda citrifolia L.). Anais do Congresso Técnico Científico da Engenharia e da Agronomia, Foz do Iguaçu, PR, Brasil.

Lomauro, C. J., Bakshi, A. S., \& Labuza, T. P. (1985). Evaluation of food moisture sorption isotherm equations. Part I: fruit, vegetable and meat products. Lebensmittel-Wissenschaft \& Techonologies, 18(2), 111-117.

Luchese, C. L., Frick, J. M., Patzer, V. L., Spada, J. C., \& Tessaro, I. C. (2015). Synthesis and characterization of biofilms using native and modified pinhão starch. Food hydrocolloids, 45, 203-210.

MAPA. Ministério da Agricultura, Pecuária e Abastecimento. (2009). Regras para análise de sementes. Mapa/ACS.

Martinez, A. P. C., Martinez, P. C. C., Souza, M. C., \& Brazaca, S. G. C. Alterações químicas em grãos de soja com a germinação. Ciência e Tecnologia de Alimentos, Campinas, 31(1), 23-30, 2011. dx.doi.org/10.1590/S0101-20612011000100004.

Medeiros, M. L., Ayrosa, A. M. I. B., Pitombo, R. N. M., \& Lannes, S. C. S. (2006). Sorption isotherms of cocoa and cupuassu products. Journal of Food Engineering, 73(4), 402-406. doi.org/10.1016/j.jfoodeng.2005.02.002

Miller, G. L. Use of dinitrosalicylic acid reagent for determination of reducing sugar. (1959). Analytical Cemistry, 31(3), 426-428. doi.org/10.1021/ac60147a030.

Mohan, B. H., Malleshi, N. G., \& Koseki, T. (2010). Physico- chemical characteristics and non-starch polysaccharide contents of Indica and Japonica brown rice and their malts. Food Science and Technology, 43(5), 784-791. doi.org/10.1016/j.1wt.2010.01.002.

Moongngarm, A., \& Saetung N. (2010). Comparison of chemical compositions and bioactive compounds of germinated rough rice and brown rice. Food Chemistry, 122(3), 782-788. doi.org/10.1016/j.foodchem.2010.03.053.

MORAIS, L. K. (2019). Desenvolvimento, caracterização físico-química e sensorial de biscoitos tipo" cookies" obtidos a partir da farinha da semente de abóbora (Cucurbita máxima).

Naves, L. de P., Corrêa, A. D., Abreu, C. M. P. de, \& Santos, C. D. dos. (2010). Nutrientes e propriedades funcionais em sementes de abóbora (Cucurbita maxima) submetidas a diferentes processamentos. Food Science and Technology, 30(Supl.1), 185-190.

Oliveira, E. G., Duarte, J. H., Moraes, K., Crexi, V. T. \& Pinto, L. A. A. (2010). Optimisation of Spirulina platensis convective drying: evaluation of phycocyanin loss and lipid oxidation. International Journal of Food Science and Technology, 45(8), 1572-1578. doi.org/10.1111/j.1365-2621.2010.02299.x.

Paksoy M., \& Aydin C. (2004). Some physical properties of edible squash (Curcubitapepo L.) seeds. Journal of Food Engineering. 65(2), 225-231. doi.org/10.1016/j.jfoodeng.2004.01.019.

Pumar, M., Freitas, M. C. J., Cerqueira, P. M., \& Santangelo, S. B. (2008). Avaliação do efeito fisiológico da farinha de semente de abóbora (Cucurbita máxima L.) no trato intestinal de ratos. Ciência e Tecnologia de Alimentos, 28(suppl.0), 7-13. doi.org/10.1590/S0101-20612008000500002.

Sant'Anna, L. C. (2005). Avaliação da composição química da semente de abóbora (Cucurbita pepo) e do efeito do seu consumo sobre o dano oxidativo hepático de ratos (Rattus novergicus) (Dissertação de mestrado). Universidade Federal de Santa Catarina, Florianópolis, SC, Brasil.

Santos, A. A. C., Florêncio, A. K. G. D., Rocha, E. M. F. F., \& Costa, J. M. C. (2014). Avaliação físico-química e comportamento higroscópico de goiaba em pó obtida por spray-dryer. Revista Ciência Agronômica, 45(3), 508-514. doi.org/10.1590/S1806-66902014000300010

Silva, E. O., Almeida, A. R. F., \& Oliveira, L. C. (2016). Estudo da cinética de secagem de sementes de cevadilha vacariana (Bromus auleticus T.). Anais do Salão Internacional de Ensino, Pesquisa e Extensão, Uruguaiana, 2016, Uruguaiana, RS, Brasil, 8.

Silva, E. T. V., Moura, H. V., dos Santos, F. S., \& Tomiyoshi, C. M. (2020). Prospecção Tecnológica sobre Amendoim Germinado Aplicado à Tecnologia de Alimentos. Cadernos de Prospecção, 13(1), 213.

Silva, F. A. S., \& Azevedo, C. A. V. (2016). The Assistat Software version 7.7 and its use in the analysis of experimental data. African Journal of Agricultural Research, 11(39), 3733- 3740, 2016

Silva, J. S. Barra de cereais elaboradas com farinha de semente de abóbora [dissertação]. Lavras, MG: Programa de Pós-Graduação em Agroquímica, Universidade Federal de Lavras, 2012 
Research, Society and Development, v. 10, n. 3, e18810313005, 2021

(CC BY 4.0) | ISSN 2525-3409 | DOI: http://dx.doi.org/10.33448/rsd-v10i3.13005

Silva, S. F., Lemos, D. M., Silva, F. B., Figueirêdo, R. M. F. de, \& Sousa, E. P. de. (Setembro, 2015). Isotermas de adsorção de água da farinha das fibras residuais secas de manga. Anais do Congresso Técnico Científico da Engenharia e da Agronomia, Fortaleza, CE, Brasil.

Telis, V. R. N., \& Sobral, P. J. A. (2001). Glass transitions and state diagram for freeze-dried pineapple. Lebensmittel Wissenchaft u. Technology, 34(4), 199205. doi.org/10.1006/fstl.2000.0685.

Tian, B., Xie, B., Shi. J., Wu, J., Cai, Y., Xu, T., Xue, S., \& Deng, Q. (2010). Physicochemical changes of oat seeds during germination. Food Chemistry, 119(3), 1195-1200, 2010. doi.org/10.1016/j.foodchem.2009.08.035.

Veronezi, C., \& Jorge, N. (2011). Carotenoides em abóboras. Boletim do Centro de Pesquisa de Processamento de Alimentos, 29(1), 9-20, 2011. Recuperado de https://revistas.ufpr.br/alimentos/article/view/22734/16744.

Vidal, M. D. (2007). Potencial fisiológico e tamanho de sementes de abóbora (Dissertação de mestrado). Universidade Federal de Santa Maria, Santa Maria, RS, Brasil.

Villela, F. A., Novembre, A. D. L. C., \& Marcos Filho, J. (2007). Estado energético da água na germinação de sementes de soja. Revista Brasileira de Sementes, 29(1), 27-34. doi.org/10.1590/S0101-31222007000100004.

Yemm, E. W., \& Willis, A. J. (1954). The estimation of carbohydrates in plan extracts by anthrone. Biochemical Journal, 57(3), 508-5015. 10.1042 / bj0570508. 